\title{
Plant community characteristics and degradation mechanisms of the desert riparian zone in the lower reaches of the Ugan River, China
}

\author{
TJ Z ${ }^{1}$, yaning Chen ${ }^{2}$, Jiazhen Liư ${ }^{3}$, and Yongjin $\mathrm{Chen}^{3}$ \\ ${ }^{1}$ State Key Laboratory of Desert and Oasis Ecology \\ ${ }^{2}$ Xinjiang Institute of Ecology and Geography, Chinese Academy of Sciences, Urumqi, \\ ${ }^{3}$ School of Environment and Planning, Liaocheng University
}

January 8, 2021

\begin{abstract}
The vegetation in the desert riparian zone represents a critical barrier in the maintenance of the ecosystem's balance. However, in recent years, the vegetation degradation of the riparian zone have seriously hindered economic development and ecological environment conservation. Based on a field investigation and literature, the mechanisms of vegetation degradation in the lower reaches of the Ugan River are discussed in this study through the analysis of plant coverage, diversity, substitution rate, distribution pattern, grey correlation analysis, and the relationship with groundwater depth. The results showed that the vegetation coverage in this region is relatively low when the water depth exceeds 4 meters. Furthermore, the Shannon-Wiener index, the Simpson index and the Pielou index have all decreased with increases in water depth. Woody plants are the main species maintaining the ecological balance of the region with an aggregation distribution pattern. The degradation of vegetation is the result of the lack of water sources and intense water consumption caused by human activities(especially agricultural). To promote the ecological balance and vegetation restoration, the relative optimal water depth range can be maintained within 2 to 5 meters and proper control human activities.besides the degraded vegetation can gradually be restored using point and surface (i.e., flowering in the center and spreading to the surrounding areas).
\end{abstract}

\section{Hosted file}

Plant communitycharacteristics and degradation mechanism of desert riparian zone in thelower reaches of available at https://authorea.com/users/388159/articles/502989-plant-communitycharacteristics-and-degradation-mechanisms-of-the-desert-riparian-zone-in-the-lowerreaches-of-the-ugan-river-china 